Article

\title{
Structurally and Compositionally Tunable Absorption Properties of AgCl@AgAu Nanocatalysts for Plasmonic Photocatalytic Degradation of Environmental Pollutants
}

\author{
Han-Jung Ryu ${ }^{\dagger}$, Ha-Lin Kim ${ }^{\dagger}$, Jang Ho Joo and Jae-Seung Lee *D \\ Department of Materials Science and Engineering, Korea University, 145 Anam-ro, Seongbuk-gu, \\ Seoul 02841, Korea \\ * Correspondence: JSLEE79@korea.ac.kr \\ + These authors contributed equally.
}

Received: 3 March 2020; Accepted: 4 April 2020; Published: 8 April 2020

\begin{abstract}
Composite nanomaterials having Ag nanoparticles (NPs) that decorate nanostructured $\mathrm{AgCl}(\mathrm{Ag} / \mathrm{AgCl})$ are promising as plasmonic photocatalysts because of the visible-light absorption of Ag NPs. However, the narrow absorption bands of Ag NPs near $400 \mathrm{~nm}$ cause inefficient absorption in the visible range and, consequently, unsatisfactory photocatalytic activity of $\mathrm{Ag} / \mathrm{AgCl}$ nanomaterials. In this study, we introduce a new class of AgCl-based photocatalysts that are decorated with bimetallic $\mathrm{Ag}$ and $\mathrm{Au}$ NPs (AgCl@AgAu NPs) for visible-light-driven photocatalytic degradation of organic pollutants. Polyvinylpyrrolidone induces selective reduction of noble metal precursors on $\mathrm{AgCl}$ while leaving $\mathrm{AgCl}$ intact. The extended composition of the decorating NPs red-shifts the absorption band to 550-650 nm, which allows the catalysts to take advantage of more energy in the visible range for improved efficiency. Furthermore, we control the structures of the AgCl@AgAu NPs, and investigate their correlation with photocatalytic properties. The versatility, chemical stability, and practical application of the AgCl@AgAu NPs are demonstrated using various organic pollutants, recycling experiments, and natural aqueous media, respectively. Our fundamental investigation on the synthesis and applications of $\mathrm{AgCl}$-based nano-photocatalysts is highly valuable for designing plasmonic photocatalysts and expanding their utilization.
\end{abstract}

Keywords: $\mathrm{AgCl}$; gold; silver; nanoparticle; surface plasmon resonance; photocatalyst; visible light; organic pollutant; PVP

\section{Introduction}

Silver chloride $(\mathrm{AgCl})$ is a crystalline material that is readily prepared by aqueous precipitation at room temperature because of its low water solubility $\left(K_{\mathrm{sp}}=1.77 \times 10^{-10}\right.$ at $\left.25^{\circ} \mathrm{C}\right)$ [1]. Based on its facile synthesis and semiconductive electronic properties (band gap $=3.19 \mathrm{eV}$ ), $\mathrm{AgCl}$ has been used in various applications such as photosensitizers, reference electrodes, and photocatalysts [2-4]. Recently, the scientific interest in $\mathrm{AgCl}$ has been extended to its nanoscale synthesis, leading to significant progress in chemical control over the shape and size of $\mathrm{AgCl}$. As a result, $\mathrm{AgCl}$ nanomaterials with various shapes such as plate, cubic, spherical, and octahedral could be synthesized [5-10]. In addition to pure $\mathrm{AgCl}$, composite nanostructures composed of $\mathrm{AgCl}$ and noble metals have recently been synthesized [5,6,11-13]. However, most of the composite nanostructures were still compositionally limited to $\mathrm{Ag} / \mathrm{AgCl}$, whose sizes and shapes, and corresponding chemical and physical properties, were hardly controlled [14-17]. These shortcomings mainly originated from the limited synthetic conditions of noble metal/AgCl composite nanostructures. The bottom-up synthesis of noble 
metal nanostructures is essentially conducted by reducing their metallic precursors. Under such reductive conditions, however, $\mathrm{AgCl}$ nanostructures are readily reduced and deformed into metallic Ag debris $[5,6,11]$. Therefore, the chemically controlled selective reduction of metallic precursors in which $\mathrm{AgCl}$ structures are preserved is highly desired for synthesizing noble metal/ $\mathrm{AgCl}$ composites and controlling their properties.

Environmental pollution by organic pollutants has been an important issue since the First Industrial Revolution. To solve the problem, photocatalytic degradation of organic materials has been proposed as a practical solution [18-21]. For a few decades, $\mathrm{TiO}_{2}$ nanomaterials have been widely investigated as typical photocatalysts [22-25]. $\mathrm{TiO}_{2}$ photocatalysts exhibit long-term chemical stability, inertness, and non-toxicity, which lead to various catalytic applications [26]. Owing to its wide band gap (3.2 eV), however, pure $\mathrm{TiO}_{2}$ is mainly activated by ultraviolet (UV) light, which comprises only $10 \%$ of the entire sunlight radiation on the Earth [27]. Since the proportion of visible light in sunlight radiation is approximately $40 \%$, which is four times that of UV light, the low photocatalytic activity of $\mathrm{TiO}_{2}$ could be considerably enhanced by extending the absorption to the visible range. One of the leading strategies involves combining $\mathrm{TiO}_{2}$ photocatalysts with additional noble metal (e.g., $\mathrm{Au}$ and $\mathrm{Ag}$ ) nanostructures [28-31]. The noble metal nanostructures can absorb visible light based on their localized surface plasmon resonance (LSPR). The plasmonic absorption of noble metals can assist the separation of absorbed visible light into holes and electrons in $\mathrm{TiO}_{2}$. This plasmonic absorption extends the photocatalytic activity of $\mathrm{TiO}_{2}$ into the visible region. However, the harsh synthetic conditions of $\mathrm{TiO}_{2}$-based photocatalysts, such as high reaction temperature and use of strong acids ( $\mathrm{HF}$ or $\mathrm{HCl}$ ), hinder the wide application of $\mathrm{TiO}_{2}$ photocatalysts. Therefore, alternative visible-light photocatalytic materials that are easily synthesized using environmentally benign reagents, preferably at room temperature, must be developed.

Herein, we present the chemically controlled aqueous synthesis of $\mathrm{AgCl} /$ noble metal composite photocatalysts with different shapes and sizes at room temperature using mild reagents. Polyvinylpyrrolidone (PVP) was chosen as a selective reductant that reduces only metallic precursors, leading to the pronounced growth of multiple metallic bumps on the surface of $\mathrm{AgCl}$. The structure-dependent photocatalytic activity of $\mathrm{AgCl} /$ noble metal composite nanomaterials under irradiation of visible light was successfully demonstrated for the degradation of various organic pollutants.

\section{Results and Discussion}

The overall synthetic procedure of AgCl-based nanocatalysts is depicted in Scheme 1. In general, PVP acts as a shape-directing agent in the synthesis of $\mathrm{AgCl}$ nanomaterials, as well as a mild reductant at high concentrations [5,32]. For the reduction of the metallic precursors into metallic bumps, the final PVP concentration was set to be high $(5.356 \mathrm{~g} / \mathrm{L})$ for the synthesis of spherical $\mathrm{AgCl}$ nanomaterials decorated with noble metal ( $\mathrm{Au}$ and $\mathrm{Ag}$ ) nanoparticles (AgCl@AgAu NPs). As the required PVP concentration for the synthesis of cubic $\mathrm{AgCl}$ nanomaterials is considerably lower, however, cubic $\mathrm{AgCl}$ nanomaterials were synthesized at a much lower PVP concentration $(0.0357 \mathrm{~g} / \mathrm{L})$. For the growth of metallic bumps, the PVP concentration was later increased to $5.356 \mathrm{~g} / \mathrm{L}$. It is commonly known that the molecular weight (MW) of polymers plays a variety of roles in synthesizing noble metal NPs [32]. To investigate the effect of polymer MW on the structural, plasmonic, and photocatalytic properties of the AgCl@AgAu NPs, we synthesized the AgCl@AgAu NPs using PVP with various MWs (monomeric vinyl pyrrolidone, 10,000 (10k), 29,000 (29k), 55,000 (55k), and 360,000 (360k)) (Figure 1). When monomer was used, only significantly aggregated small AgCl@AgAu NPs ( 45 nm in diameter) were obtained (Figure 1a). The instability of these AgCl@AgAu NPs is due to incomplete passivation by monomeric vinyl pyrrolidone, whose binding affinity is limited compared to that of chelating PVP $[33,34]$. As the polymer MW was increased, the average size of the resultant AgCl@AgAu NPs also increased, eventually becoming as large as $220 \mathrm{~nm}$ in diameter (Figure $1 \mathrm{~b}-\mathrm{d}$ ). When the longest PVP was used (MW = 360k), however, the size of the AgCl@AgAu NPs decreased (Figure 1e). There are 
two chemical mechanisms that can explain our observations. First, the large MW of PVP can inhibit the initial crystallization of $\mathrm{AgCl}$, which is attributed to the decreased seed concentration and increased size of the NPs in the context of seed-mediated growth [35-37]. Second, the increase in PVP MW can inhibit the ripening of silver halide NPs, resulting in smaller silver halide NPs [38]. In our work, the first mechanism was dominant as the MW of PVP increased from 10k to 55k, while the second mechanism was dominant from 55k to 360k, resulting in the largest AgCl@AgAu NPs with 55k PVP. The MW of PVP also influenced the LSPR properties of the AgCl@AgAu NPs (Figure 1f). The metallic bumps on the AgCl@AgAu NPs with 10k and 360k PVP were more pronounced, resulting in strong plasmonic absorption near 550 nm, while the large two the AgCl@AgAu NPs with 29k and 55k PVP exhibited weaker plasmonic absorption. The monomeric vinyl pyrrolidone led to broad scattering owing to aggregated structures, as observed in Figure 1a. The photocatalytic activities of the AgCl@AgAu NPs for degradation of an organic dye were evaluated using amaranth as a model dye, which is a common organic pollutant in the dye industry, but is hardly degradable (Figure 1g) [39]. Interestingly, 55k PVP-AgCl@AgAu NPs exhibited the largest photocatalytic activity, which could be attributed to their reasonably strong LSPR and chemical stability based on their large diameter (220 $\mathrm{nm}$ in diameter).

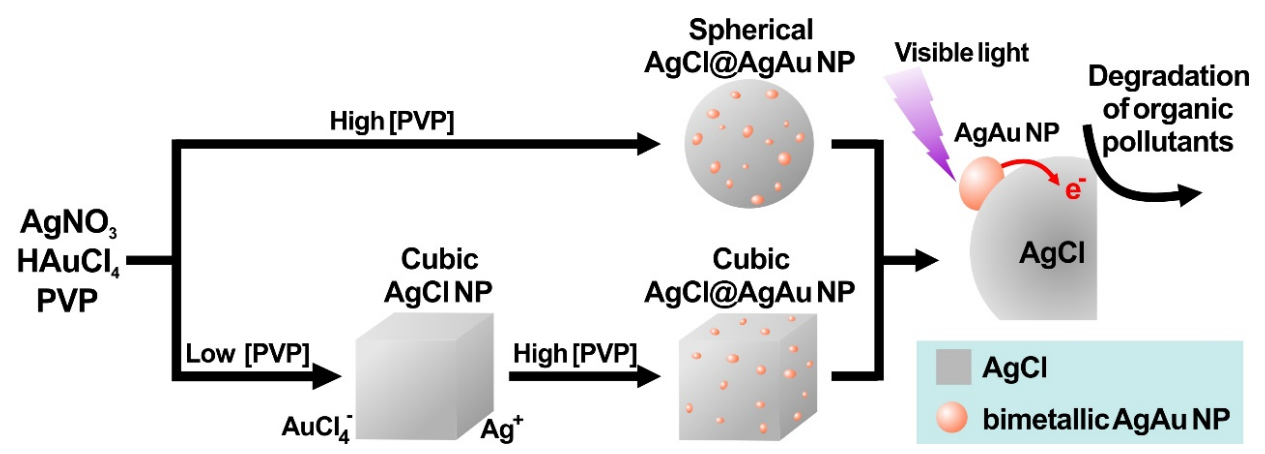

Scheme 1. Synthetic scheme of cubic and spherical AgCl@AgAu nanoparticles (NPs). The shape of the $\mathrm{AgCl} @ \mathrm{AgAu}$ NPs is controlled by the initial concentration of polyvinylpyrrolidone (PVP). The final concentration of PVP is adjusted to be the same for the same reductive conditions. The resultant $\mathrm{AgCl} \mathrm{AgAu}$ NPs are used for the photocatalytic degradation of organic pollutants under visible light irradiation.
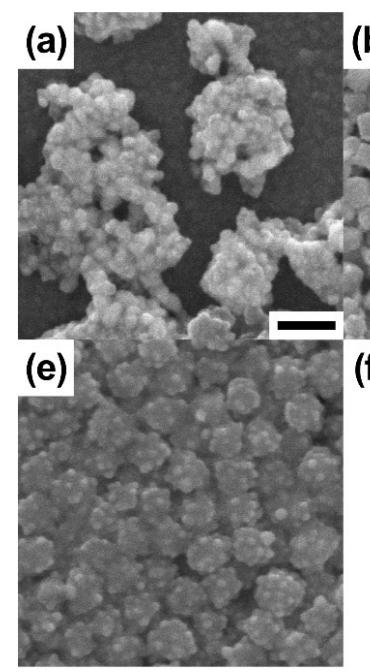
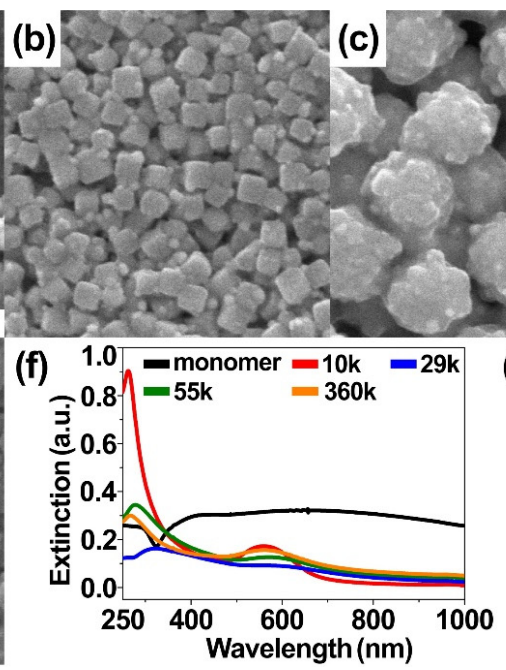

(d)

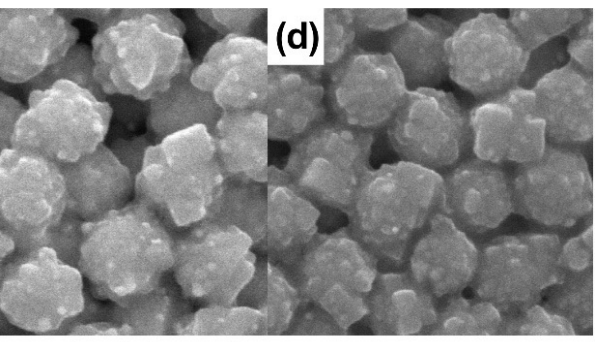

(g)

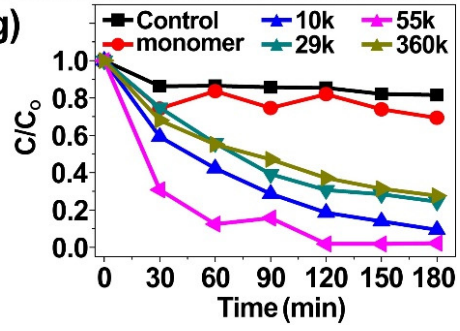

Figure 1. (a-e) SEM images of the AgCl@AgAu NPs synthesized with PVP having different molecular weights. (a) Monomeric vinyl pyrrolidone, (b) 10,000 (10k), (c) 29,000 (29k), (d) 55,000 (55k), and (e) 360,000 (360k). The scale bar is 200 nm. (f) UV-vis spectra of the AgCl@AgAu NPs synthesized with PVP having different molecular weights. (g) Time-dependent photocatalytic degradation of amaranth with the AgCl@AgAu NPs synthesized with PVP having different molecular weights. 
Plasmonic absorption significantly affects the photocatalytic activity because it facilitates the separation of absorbed visible light into holes and electrons. Therefore, the enhanced absorption by larger metallic bumps improves the photocatalytic properties. On the other hand, the presence of such larger bumps decreases the exposed surfaces of $\mathrm{AgCl}$ NPs where the catalytic reactions actually occur, resulting in lower photocatalytic properties. In order to investigate which effect is dominant, we chose the AgCl@AgAu NPs synthesized with 55k PVP as a control and grew their bumps in a growth solution, which was analyzed using SEM (Figure 2a,b). The growth of the bumps was further analyzed using UV-vis spectroscopy, where the extinction dramatically increased owing to the increased plasmonic absorption and scattering of the enlarged metallic bumps (Figure 2c). The reduction of $\mathrm{Ag}^{+}$on the initial metallic bumps also induced a significant spectral blue shift from 550 to $420 \mathrm{~nm}$. After confirming the successful growth of the metallic bumps, we compared the photocatalytic properties of the two types of the AgCl@AgAu NPs with different sizes of metallic bumps (Figure 2d). Interestingly, despite the increased plasmonic absorption, the photocatalytic activity decreased substantially. The control AgCl@AgAu NPs induced the completion of the reaction after $90 \mathrm{~min}$ (95\% completion), while the reaction in the presence of the AgCl@AgAu NPs with larger bumps was still in process even at $180 \mathrm{~min}$ (70\% completion). This limited photocatalytic activity caused by the larger metallic bumps clearly indicates that the effect of surface masking of $\mathrm{AgCl}$ by the metallic bumps is strong enough to suppress the effect of increased plasmonic absorption. Based on our observations, it is necessary that the metallic bumps are designed to be small enough to expose sufficient $\mathrm{AgCl}$ surfaces for the photocatalytic reaction. However, the bumps should at least be large enough to exhibit plasmonic properties. We also evaluated the effect of the size of $\mathrm{AgCl}$ nanomaterials on the photocatalytic activity of the $\mathrm{AgCl} @ \mathrm{AgAu}$ NPs which, however, turned out to be negligible (Figure S1) [5].
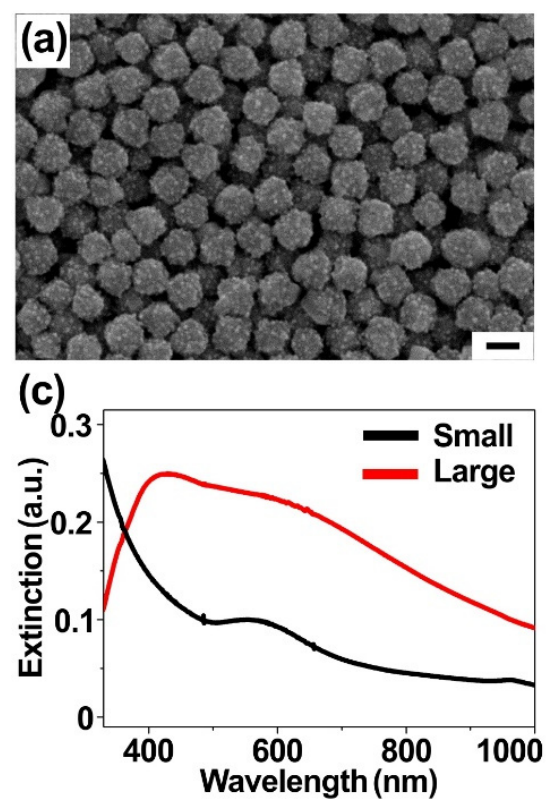

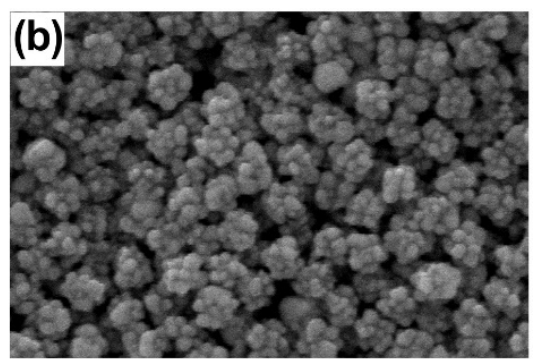

(d)

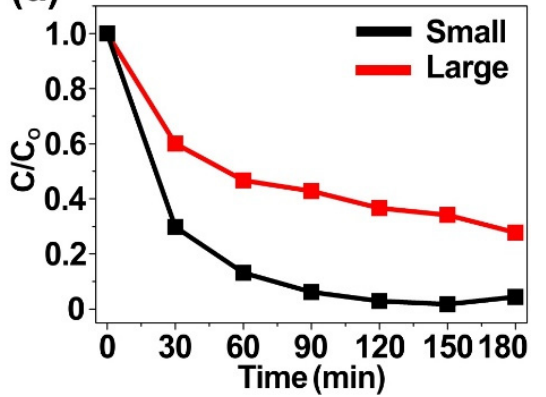

Figure 2. (a,b) SEM images of the AgCl@AgAu NPs with (a) small metallic bumps and (b) large metallic bumps which were grown from the ones in Figure 2a. The scale bar is $200 \mathrm{~nm}$. (c) UV-vis spectra of the AgCl@AgAu NPs with small and large bumps. (d) Time-dependent photocatalytic degradation of amaranth with the AgCl@AgAu NPs with small and large bumps.

The shape of NPs is crucial to determine their usage as catalysts. The exposed particle surface exhibits different surface potentials and consequently different catalytic properties depending on the crystalline facets. Therefore, cubic crystalline $\mathrm{AgCl}$ particles with (200) facets are expected to exhibit different photocatalytic activity from that of spherical $\mathrm{AgCl}$ particles with mixed facets. As the PVP concentrations required for the synthesis of cubic $\mathrm{AgCl}$ particles and for the reduction of metallic precursors are different $(0.0357 \mathrm{~g} / \mathrm{L}(1 \mathrm{X}$ PVP) and $5.356 \mathrm{~g} / \mathrm{L}$ (150X PVP), respectively) [5], we first 
synthesized cubic AgCl NPs at $0.0345 \mathrm{~g} / \mathrm{L}$ of PVP, and then formed metallic bumps on the cubic $\mathrm{AgCl}$ NPs by increasing the PVP concentration to $5.356 \mathrm{~g} / \mathrm{L}$ using concentrated PVP solution. To evaluate the effect of the MW of PVP on the shape and size of the resultant NPs, we conducted the synthesis using PVP with various MWs (monomeric vinyl pyrrolidone, 10k, 29k, 55k, and 360k). While monomeric vinyl pyrrolidone resulted in highly aggregated NPs with a poorly controlled shape (Figure 3a) as we observed with the spherical $\mathrm{AgCl}$ particles (Figure 1a), the other polymeric vinyl pyrrolidone successfully resulted in the cubic AgCl@AgAu NPs with tiny metallic bumps on the surfaces, and with similar sizes and structures regardless of the MWs (Figure 3b-e). Interestingly, the bumps were much smaller than those on the spherical AgCl@AgAu NPs (Figure 1b-e). This observation indicates that $\mathrm{Au}$ and Ag were more actively nucleated on the spherical AgCl@AgAu NPs than the cubic ones, probably because of their high surface potentials based on the high-index facets [40]. Although the size difference of the tiny metallic bumps was hardly observed using SEM, their plasmonic properties were still observed by the shoulders of the UV-vis spectra around $600 \mathrm{~nm}$ (Figure 3f). Based on the absorption of the cubic AgCl@AgAuNPs in the visible range, the photocatalytic activities of the cubic AgCl@AgAuNPs depending on the MW of PVP were investigated using amaranth (Figure 3g). As the visible-range absorption was relatively weak, the photocatalytic activity was mainly determined by the size-dependent stability of the cubic AgCl@AgAuNPs. The largest AgCl@AgAuNPs (edge length $=\sim 340 \mathrm{~nm}$ ), synthesized with 55k PVP (Figure 3d), exhibited the highest photocatalytic activity, which was followed by that of the AgCl@AgAuNPs synthesized with 29k PVP (Figure 3c). As observed with the spherical AgCl@AgAu NPs (Figure 1), the cubic AgCl@AgAu NPs synthesized with 55k PVP were determined to be the most stable and the fastest photocatalysts. The importance of the MW of PVP was also demonstrated by the almost consistent photocatalytic activity of the AgCl@AgAu NPs synthesized with 55k PVP regardless of their shapes (Figure S2). In fact, however, the shape of the AgCl@AgAu NPs played an important role in determining their chemical stability under elongated reaction conditions $(24 \mathrm{~h}$ ), proposing the one synthesized with 10X PVP during the $\mathrm{AgCl}$ formation and 150X PVP during the reduction exhibited the greatest stability (10X AgCl@AgAu NPs; Figure S3).
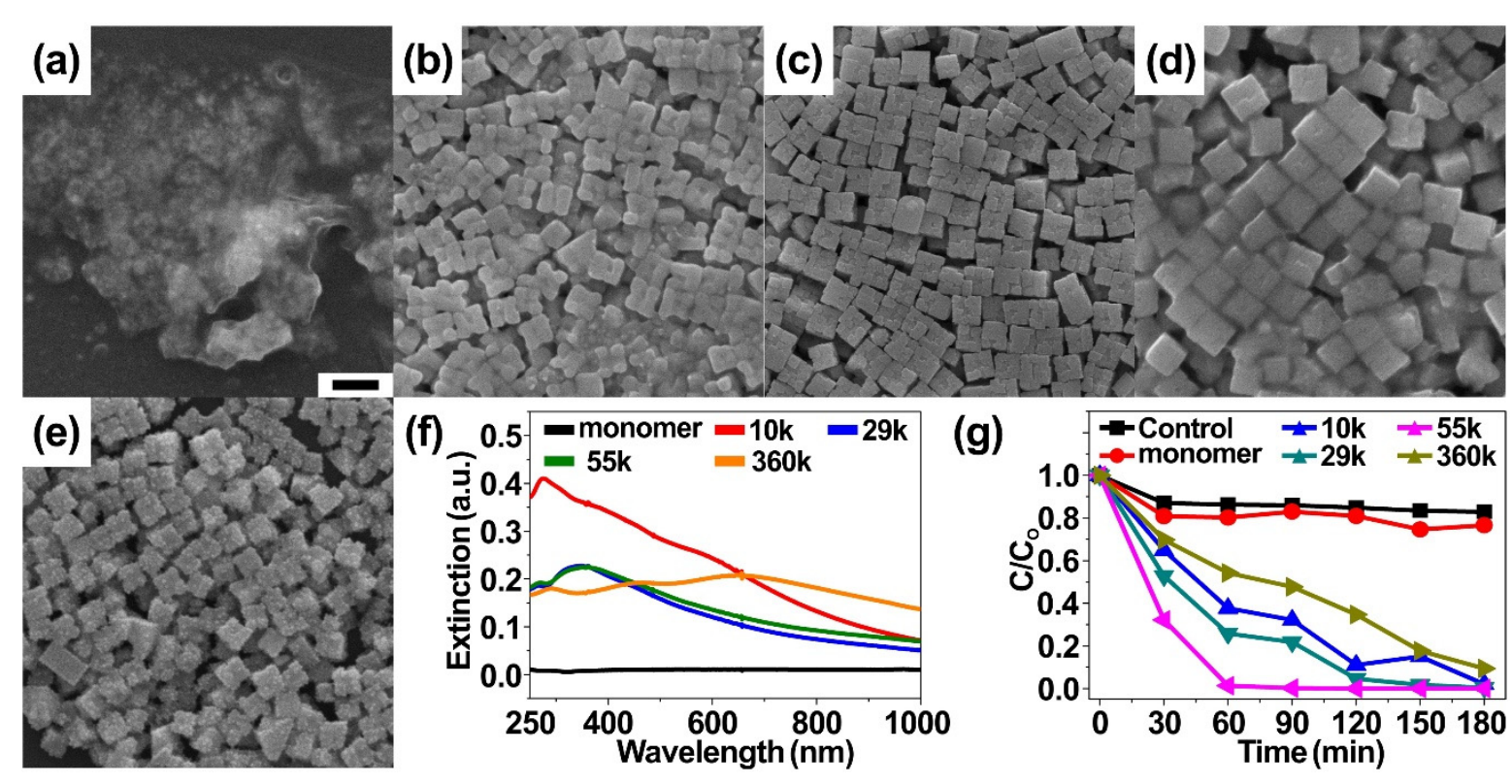

Figure 3. (a-e) SEM images of the cubic AgCl@AgAu NPs with PVP having different MWs. (a) Monomeric vinyl pyrrolidone, (b) 10,000 (10k), (c) 29,000 (29k), (d) 55,000 (55k), and (e) 360,000 (360k). (f) UV-vis spectra of the cubic AgCl@AgAu NPs synthesized with PVP having different MWs. (g) Time-dependent photocatalytic degradation of amaranth with the cubic AgCl@AgAu NPs synthesized with PVP having different MWs. 
The crystalline structures of the AgCl@AgAu NPs were analyzed at each step of the synthesis using X-ray diffraction (XRD) (Figure 4). Based on the excellent stability and photocatalytic performance, 10X $\mathrm{AgCl} @ \mathrm{AgAu}$ NPs were chosen as a representative photocatalyst for the analysis. The quantum yield of the degradation of amaranth using 10X AgCl@AgAu NPs as photocatalysts is determined to be $\sim 0.35 \%$, which is as good as those reported with regard to the conventional $\mathrm{TiO}_{2}$ photocatalysts $(\sim 0.2 \%)$ [41]. Before the reduction of the metallic precursors, the 10X AgCl NPs ( $\mathrm{AgCl} \mathrm{NPs} \mathrm{that} \mathrm{is} \mathrm{synthesized} \mathrm{with}$ 10X PVP) exhibited a strong (200) peak at $32^{\circ}$ owing to stacking of the truncated cubic AgCl particles, along with a few weaker peaks at 28,46 , and $67^{\circ}$ in the XRD pattern. This pattern exactly matched that of the standard $\mathrm{AgCl}$ reference (JCPDS No. 01-1013), elucidating the crystalline nature of the AgCl NPs. After the formation of metallic bumps, we observed a few more new peaks at $38,44,64,78$, and $82^{\circ}$ in the XRD pattern, which showed the formation of metallic Au and Ag bumps on the AgCl NPs. Because the metallic bumps were too small to be clearly observed using SEM, their peaks were broader than those of the $\mathrm{AgCl}$ NPs [42]. However, their overall XRD pattern was distinctive enough to identify the presence of metallic $\mathrm{Au}$ and $\mathrm{Ag}$, indicating that the number of metallic bumps was still considerable.

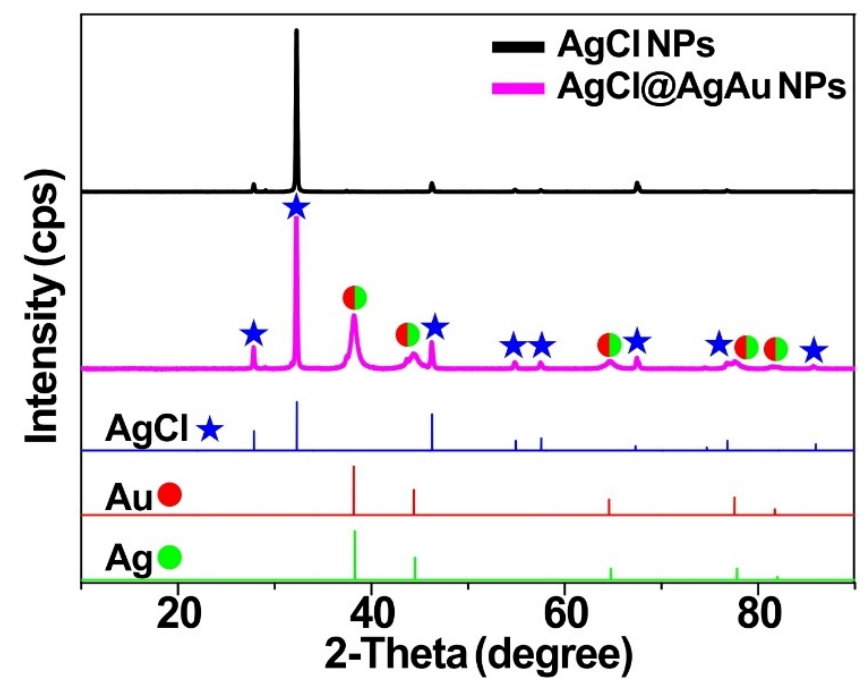

Figure 4. XRD patterns of the 10X AgCl NPs (black) and the 10X AgCl@AgAu NPs (pink). Reference JCPDS patterns for each element are shown below ( $\mathrm{AgCl}$ in blue, $\mathrm{Au}$ in red, and $\mathrm{Ag}$ in green).

The metallic bumps were further investigated with respect to their structural and plasmonic properties using transmission electron microscopy (TEM) and UV-vis spectroscopy. As the observation of the metallic bumps on the surface of the AgCl@AgAu NPs was limited due to the presence of AgCl, we first eliminated the AgCl NPs of the 10X PVP AgCl@AgAu NPs using $\mathrm{NH}_{3}$ and collected the remaining bimetallic AgAu NPs for TEM investigation. The metallic bumps were in general smaller than $10 \mathrm{~nm}$ (Figure 5a), which explains why they were not clearly observed using SEM in Figure S2c. The distribution of $\mathrm{Au}$ and $\mathrm{Ag}$ was determined by energy dispersive $\mathrm{X}$-ray spectroscopy and shown in elemental maps (Figure 5b-d). Most of the bumps contained both $\mathrm{Au}$ and $\mathrm{Ag}$ at an atomic ratio of 25 and 75, which is similar to the mole ratio of remaining $\mathrm{AuCl}_{4}{ }^{-}$and $\mathrm{Ag}^{+}$(approximately 1:3 or 1:4) after the synthesis of the AgCl NPs. [43,44] The interplanar spacing of the AgAu NP bumps was determined to be $0.23 \mathrm{~nm}$ using high-resolution TEM (Figure 5e), which matches the literature values of (111) planes of pure Au and Ag [45]. These dispersed metallic bumps exhibited a strong absorption band in the visible range ( $\sim 550-650 \mathrm{~nm})$, which is due to their LSPR as a result of their composition (Au and Ag) and size (approximately $10 \mathrm{~nm}$ or smaller) (Figure 5f). Interestingly, this absorption band is hardly observed in the UV-vis spectrum of the initial AgCl@AgAu NPs (Figure S2f), probably because of the short interparticle distances between the bumps on the $\mathrm{AgCl} \mathrm{NPs}$ and consequent interference of electromagnetic waves [46]. 


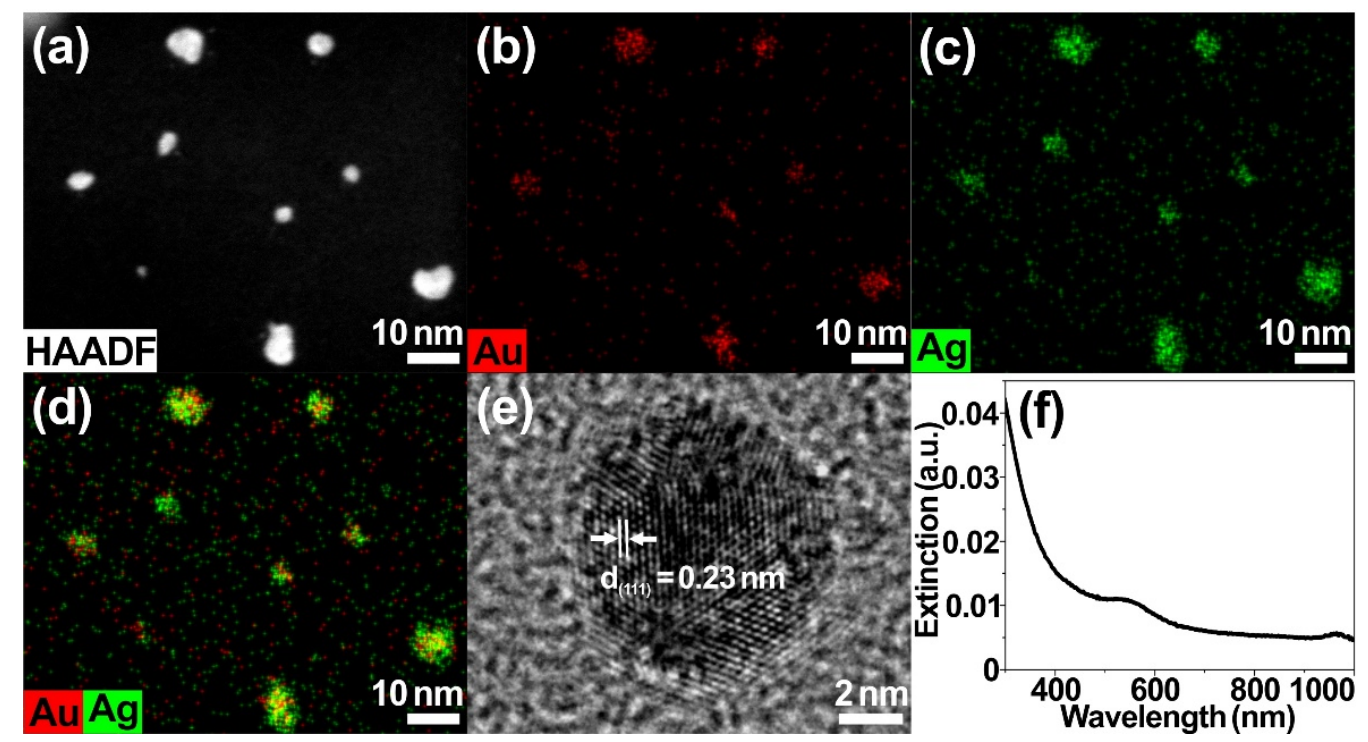

Figure 5. (a) High-angle annular dark-field (HAADF) scanning TEM image of the metallic bumps after removal of the AgCl NPs from the AgCl@AgAu NPs. Elemental distributions of (b) Au, (c) Ag, and (d) their overlaps are demonstrated. (e) High resolution TEM image of a single AgAu NP. The interplanar spacing is illustrated, which matches those of bulk Au and Ag in literature. (f) UV-vis spectrum of the AgAu NPs after removal of AgCl. The absorption band around 550-650 nm is a result of the uncontrolled aggregation of nanosized metallic $\mathrm{Ag}$ and $\mathrm{Au}$ and the consequent red-shift of their individual absorption bands.

In addition to the correlation between the structures and photocatalytic properties of the AgCl@AgAu NPs, we examined the effect of visible light irradiation on the photocatalytic reactions. In fact, it is possible that the catalytic reactions rely on metal-based catalysis owing to the presence of metallic nanostructures of the AgCl@AgAu NPs. To evaluate this hypothesis, we conducted the oxidation of amaranth in the presence of 10X PVP AgCl@AgAu NPs and 10X AgCl NPs with or without visible light irradiation. In the absence of visible light, the difference between the photocatalytic activities of the AgCl NPs and the AgCl@AgAu NPs was negligible. This observation indicates that metal-based catalysis based on the metallic bumps is insignificant. In the presence of visible light, however, more than $80 \%$ of amaranth was oxidized with the AgCl@AgAu NPs after $180 \mathrm{~min}$, while the reaction proceeded to less than $50 \%$ with the $\mathrm{AgCl} \mathrm{NPs} \mathrm{at} \mathrm{the} \mathrm{same} \mathrm{time.} \mathrm{The} \mathrm{enhanced} \mathrm{reaction}$ rate by visible light irradiation clearly proves the visible light-driven photocatalytic properties of the AgCl@AgAu NPs based on the increased visible light absorption of the metallic bumps, compared to that of the $\mathrm{AgCl} \mathrm{NPs} \mathrm{(Figure} \mathrm{6a,} \mathrm{inset).} \mathrm{To} \mathrm{further} \mathrm{evaluate} \mathrm{the} \mathrm{role} \mathrm{of} \mathrm{the} \mathrm{visible} \mathrm{light} \mathrm{irradiation,}$ it was stopped at $60 \mathrm{~min}$. Without the irradiation, only negligible degradation of amaranth was observed. Therefore, the photocatalytic degradation can be easily quenched by simply eliminating the light irradiation. Moreover, even if the metallic bumps were not intentionally grown, the $\mathrm{AgCl}$ NPs can still absorb a certain amount of visible light, potentially owing to the presence of tiny metal clusters naturally occurring on the $\mathrm{AgCl}$ surface [7]. Taken together, the plasmonic absorption of the bimetallic AgAu NPs assists the generation of electron-hole pairs in $\mathrm{AgCl}$, which would have been hardly possible with pure $\mathrm{AgCl} \mathrm{NPs}$. The generated electrons and holes in $\mathrm{AgCl}$ induce the formation of hydroxyl radical $(\bullet \mathrm{OH})$ from $\mathrm{H}_{2} \mathrm{O}_{2}$, and hydroxyl/ $\mathrm{Cl}$ radical $(\bullet \mathrm{OH} / \bullet \mathrm{Cl})$ from $\mathrm{OH}^{-} / \mathrm{Cl}^{-}$, respectively. Eventually, the radical species $(\bullet \mathrm{OH}$ and $\bullet \mathrm{Cl})$ degrade the organic pollutants [47-49]. The versatility of the AgCl@AgAu NP photocatalysts for degradation of toxic organic pollutants was evaluated using other harmful organic dyes (Figure 6b). Rhodamine B (RB), Reactive Red 120 (RR), and Methylene Blue (MB) were chosen as representative harmful organic pollutants, because they are generally used in the dye industry but are highly hazardous for the environment [50-53]. Without the photocatalysts, all of the organic dyes were degraded about $20 \%$ after $180 \mathrm{~min}$ despite visible light irradiation. However, 
the batches containing the AgCl@AgAu NP photocatalysts could remove over 80\% of all the harmful organic pollutants at the same time, which demonstrated the superior and versatile photocatalytic properties of the AgCl@AgAu NPs. To demonstrate the capability of AgCl@AgAu NPs for practical applications, we evaluated the photocatalytic properties of AgCl@AgAu NPs in natural water obtained from the Han River (Seoul, Republic of Korea) using the same four dyes (amaranth (AM), RB, RR, MB) (Figure 6c). After $3 \mathrm{~h}$, approximately 60\% of the dyes was degraded by the AgCl@AgAu NPs in a photocatalytic manner. Without the catalyst, however, less than $40 \%$ of the dyes were degraded. In particular, RR degraded almost negligibly ( $<5 \%)$ without the aid of the AgCl@AgAu NPs. Even though the photocatalytic efficiency of the AgCl@AgAu NPs was decreased in natural media, the versatile and practical capability of AgCl@AgAu NPs for the removal of environmental pollutants was clearly demonstrated.
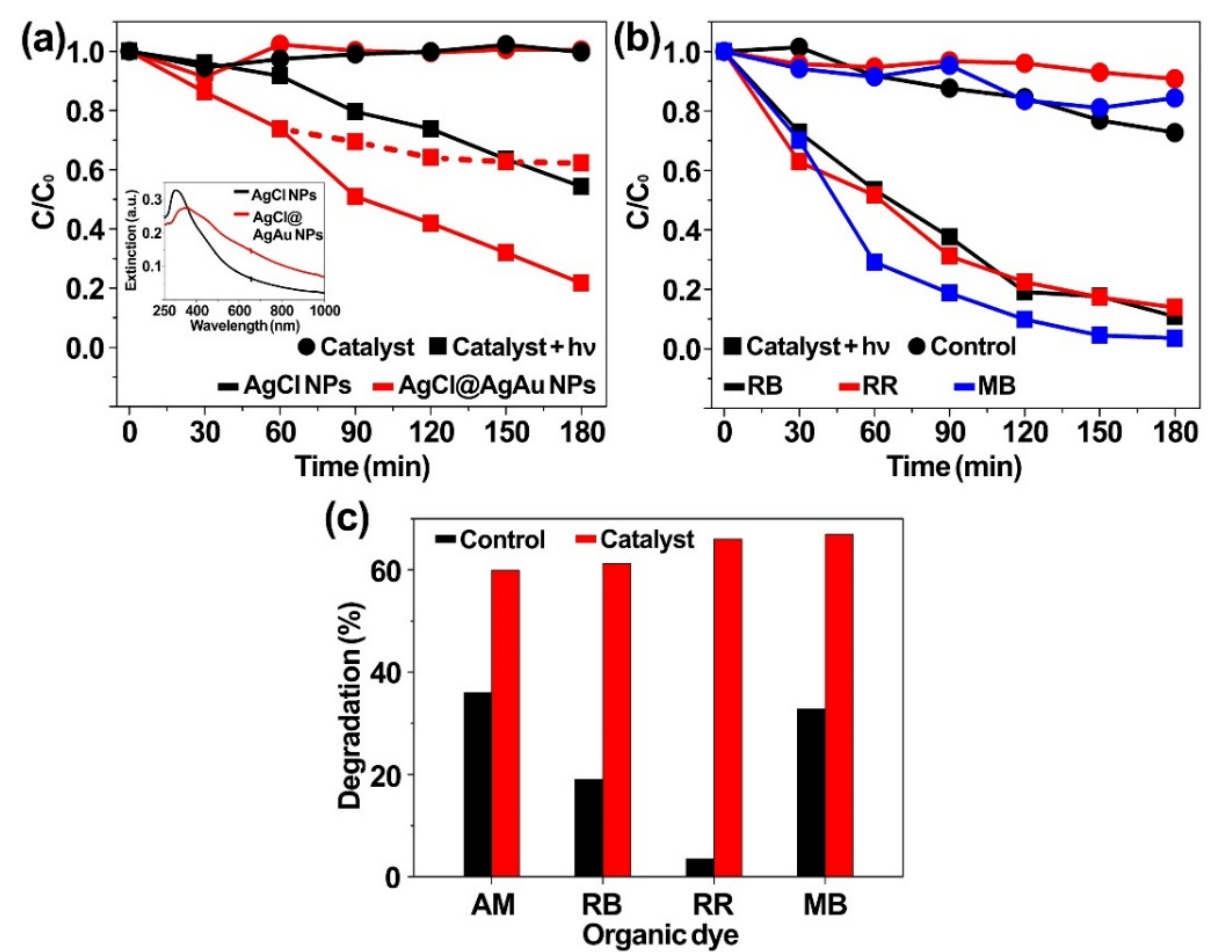

Figure 6. (a) Time-dependent photocatalytic degradation of amaranth ( $5 \mathrm{mM})$ with the AgCl NPs (black) and the AgCl@AgAu NPs (red). The progress of the reactions without visible light irradiation is plotted using circles, while the one with visible light irradiation is plotted using squares. The dashed line indicates the progress of the reactions after stopping the visible light irradiation at $60 \mathrm{~min}$. (b) Time-dependent photocatalytic degradation of multiple organic dyes (rhodamine B (RB), Reactive Red 120 (RR), and methylene blue (MB)). The progress of the reactions with visible light but without catalysts is plotted using circles, while the one with visible light and catalysts is plotted using squares. (c) Degradation of each harmful organic dye in natural media (Han River, Seoul, Republic of Korea) with and without the AgCl@AgAu NPs under the visible light irradiation after $3 \mathrm{~h}$.

The stability of heterogeneous catalysts is an important issue for reaction efficiency [54,55]. Under harsh oxidative or reductive conditions, NP catalysts could easily become non-catalytic due to their irreversible aggregation in the reaction mixture, where different phases of reactants and catalysts coexist. If NP catalysts exhibit sufficient stability to be collected after use and redispersed in a new reaction mixture, they could be repeatedly reused in multiple catalytic reactions. This recyclability would be highly advantageous in terms of cost and efficiency. Although the AgCl@AgAu NPs exhibit excellent photocatalytic properties, their stability and consequent recyclability need to be investigated, considering that they had to suffer under oxidative conditions. Therefore, the stability of the AgCl@AgAu NPs was evaluated by recycling them for the degradation of MB. The 10X PVP 
AgCl@AgAu NPs were used as a model photocatalyst for the recyclability evaluation owing to their excellent stability (Figure S3). After each photocatalytic reaction, the AgCl@AgAu NPs were collected by centrifugation and redispersed for the repeated reactions. Interestingly, MB was fully oxidized even at the 7th photocatalytic reaction (Figure 7). Moreover, the photocatalytic capability of the AgCl@AgAu NPs was maintained nearly 70\% even at the 11th reaction. This result demonstrates that the AgCl@AgAu NPs could be remarkably stable enough to be catalytically functional after repeated reactions, which is somewhat unexpected in view of the chemical instability of $\mathrm{AgCl}$ [6]. The superior recyclability and stability of the AgCl@AgAu NPs would be highly attractive for their versatile and practical photocatalytic applications.

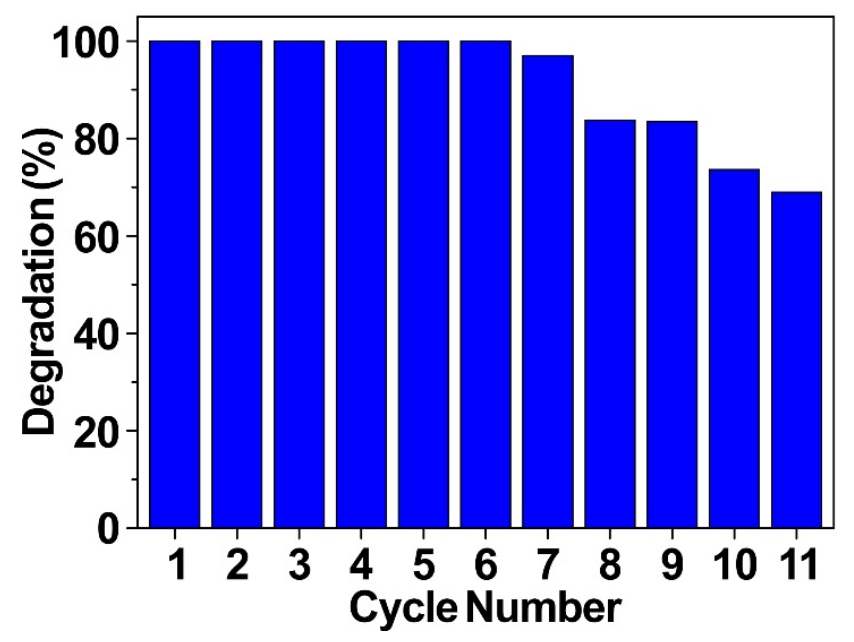

Figure 7. Degradation of methylene blue using the 10X PVP AgCl@AgAu NPs as photocatalysts used repeatedly for 11 times.

\section{Materials and Methods}

\subsection{Materials and Instruments}

Silver nitrate (cat. no. 204390), gold (III) chloride trihydrate (cat. no. 520918), polyvinylpyrrolidone (PVP) (MW = 10,000, cat. no. PVP10; MW = 29,000, cat. no. 234257; MW = 55,000, cat. no. 856568; MW $=360,000$, cat. no. PVP360), 1-vinyl-2-pyrrolidinone (cat. no. V3409), L-ascorbic acid (cat. no. A5960), amaranth (cat. no. A1016), Reactive Red 120 (cat. no. R0378), rhodamine B (cat. no. R6626), methylene blue (cat. no. M9140), hydrogen peroxide solution (cat. no. H1009), and TWEEN 20 (cat. no. P9416) were purchased from Sigma-Aldrich (St. Louis, MO, USA). Ultrapure water from a Millipore Direct-Q3 system (18.2 M $\Omega \cdot c m$; Millipore (Billerica, MA, USA)) was used for all experiments, except the evaluation of photocatalytic degradation in natural water. The natural water was collected from the Han River in Seoul, Republic of Korea, and used after filtration with a syringe filter. The metal-halide lamp was purchased from Koryo Industry ( $400 \mathrm{~W}$; Seoul, Republic of Korea). The UV cut-off filter was purchased from Edmund Optics (cat. no. 39-426, $\lambda>400 \mathrm{~nm}$; Barrington, NJ, USA). The characterization of the synthesized nanomaterials was conducted using SEM (Quanta 250 FEG, FEI; Hillsboro, OR, USA), TEM (Talos F2000X, FEI; Hillsboro, OR, USA), XRD (Smartlab, Rigaku; Tokyo, Japan), and UV-vis spectroscopy (Agilent 8453, Agilent Technologies; Santa Clara, CA, USA).

\subsection{Synthesis of AgCl@AgAu NPs}

An aqueous PVP solution (MW of PVP: monomer, 10k, 29k, 55k, and 360k; $7.045 \mathrm{~mL}, 5.356 \mathrm{~g} / \mathrm{L}$ ) was combined with an aqueous solution of $\mathrm{HAuCl}_{4}(5 \mathrm{mM}, 40 \mu \mathrm{L})$, followed by injection of an aqueous $\mathrm{AgNO}_{3}$ solution $(5 \mathrm{mM}, 200 \mu \mathrm{L})$. For the growth of $\mathrm{AgAu}$ NP bumps, the mixture was incubated with vigorous stirring at $25^{\circ} \mathrm{C}$ for $24 \mathrm{~h}$. The resultant $\mathrm{AgCl} @ \mathrm{AgAu}$ NPs were washed three times by 
centrifugation at $5000 \mathrm{rpm}$ for $5 \mathrm{~min}$, removal of the supernatant, and redispersion in a $0.01 \%$ Tween 20 solution.

\subsection{Synthesis of AgCl@AgAu NPs with Larger Metallic Bumps}

An aqueous PVP solution $(7.045 \mathrm{~mL}, 5.356 \mathrm{~g} / \mathrm{L})$ was combined with an aqueous solution of $\mathrm{HAuCl}_{4}$ $(5 \mathrm{mM}, 40 \mu \mathrm{L})$ and $\mathrm{AgNO}_{3}(5 \mathrm{mM}, 200 \mu \mathrm{L})$, and vigorously stirred at $25^{\circ} \mathrm{C}$ for $24 \mathrm{~h}$. Subsequently, the mixture was injected into an ascorbic acid solution $(180 \mu \mathrm{M}, 8 \mathrm{~mL})$ using a syringe in a drop-by-drop manner, followed by the injection of an $\mathrm{AgNO}_{3}$ solution $(5 \mathrm{mM}, 360 \mu \mathrm{L})$. The mixture was incubated with vigorous stirring for $3 \mathrm{~h}$. The synthesized AgCl@AgAu NPs with large metallic bumps were washed three times by centrifugation at $5000 \mathrm{rpm}$ for $5 \mathrm{~min}$, removal of the supernatant, and redispersion in a $0.01 \%$ Tween 20 solution.

\subsection{Synthesis of Cubic AgCl@AgAu NPs}

An aqueous PVP solution (MW of PVP: monomer, 10k, 29k, 55k, and 360k; $7.045 \mathrm{~mL}, 0.0357 \mathrm{~g} / \mathrm{L}$ ) was combined with an aqueous solution of $\mathrm{HAuCl}_{4}(5 \mathrm{mM}, 40 \mu \mathrm{L})$ and $\mathrm{AgNO}_{3}(5 \mathrm{mM}, 200 \mu \mathrm{L})$, followed by vigorous stirring at $25{ }^{\circ} \mathrm{C}$ for $30 \mathrm{~min}$. After the formation of the $\mathrm{AgCl} \mathrm{NPs}$, a concentrated aqueous PVP solution $(111.8 \mathrm{~g} / \mathrm{L}, 352 \mu \mathrm{L})$ was quickly injected to adjust the final concentration of PVP to $5.356 \mathrm{~g} / \mathrm{L}$. For the growth of the AgAu NP bumps, the mixture was incubated with vigorous stirring at $25{ }^{\circ} \mathrm{C}$ for $24 \mathrm{~h}$. The resultant cubic AgCl@AgAu NPs were washed three times by centrifugation at $5000 \mathrm{rpm}$ for $5 \mathrm{~min}$, removal of the supernatant, and redispersion in a $0.01 \%$ Tween 20 solution.

\subsection{Synthesis of AgCl@AgAu NPs with Various Sizes}

An aqueous 55k PVP solution $(7.045 \mathrm{~mL}, 5.356 \mathrm{~g} / \mathrm{L})$ was combined with an aqueous solution of $\mathrm{HAuCl}_{4}(5 \mathrm{mM})$, to which an aqueous solution of $\mathrm{AgNO}_{3}(5 \mathrm{mM})$ was added. The volume ratio of the $\mathrm{AgNO}_{3}$ and $\mathrm{HAuCl}_{4}$ solutions was determined to be 7:1, 5:1, 3:1, 2:1, or 1:1, depending on the desired size of the resultant $\mathrm{AgCl}$ nanostructures. The sum of the volumes of the two precursor solutions was $240 \mu \mathrm{L}$. For the growth of AgAu NP bumps, the mixture was incubated with vigorous stirring at $25^{\circ} \mathrm{C}$ for $24 \mathrm{~h}$. The resultant AgCl@AgAu NPs were washed three times by centrifugation at $5000 \mathrm{rpm}$ for $5 \mathrm{~min}$, removal of the supernatant, and redispersion in a $0.01 \%$ Tween 20 solution.

\subsection{Synthesis of Various Shapes of AgCl@AgAu NPs}

An aqueous PVP solution with various initial concentrations $(7.045 \mathrm{~mL}, 0.0357 \mathrm{~g} / \mathrm{L} ; 1 \mathrm{X}, 0.178 \mathrm{~g} / \mathrm{L}$; $5 \mathrm{X}, 0.357 \mathrm{~g} / \mathrm{L} ; 10 \mathrm{X}, 3.571 \mathrm{~g} / \mathrm{L} ; 100 \mathrm{X}, 5.356 \mathrm{~g} / \mathrm{L} ; 150 \mathrm{X})$ was combined with an aqueous solution of $\mathrm{HAuCl}_{4}$ $(5 \mathrm{mM}, 40 \mu \mathrm{L})$ and $\mathrm{AgNO}_{3}(5 \mathrm{mM}, 200 \mu \mathrm{L})$, followed by vigorous stirring at $25^{\circ} \mathrm{C}$ for $30 \mathrm{~min}$. After $30 \mathrm{~min}$, a concentrated aqueous PVP solution $(111.8 \mathrm{~g} / \mathrm{L})$ was quickly injected to adjust the final concentration of PVP to $5.356 \mathrm{~g} / \mathrm{L}$. For the growth of AgAu NP bumps, the mixture was incubated with vigorous stirring at $25^{\circ} \mathrm{C}$ for $24 \mathrm{~h}$. The resultant $\mathrm{AgCl} @ \mathrm{AgAu}$ NPs were washed three times by centrifugation at $5000 \mathrm{rpm}$ for $5 \mathrm{~min}$, removal of the supernatant, and redispersion in a $0.01 \%$ Tween 20 solution.

\subsection{Photocatalytic Degradation of Organic dyes}

The mass of the synthesized AgCl@AgAu NPs was calculated based on the solubility product constant (Ksp) of $\mathrm{AgCl}$ and the precursor mole ratio of $\mathrm{AgNO}_{3}$ and $\mathrm{HAuCl}_{4}$. Subsequently, the AgCl@AgAu NP solutions were diluted to have equal mass for comparison of the photocatalytic activities. The ultrapure water was added until the diluted AgCl@AgAu NPs to be dispersed in $438 \mu \mathrm{L}$ of water and combined with an organic dye solution $(2 \mathrm{mM}, 50 \mu \mathrm{L}$; amaranth, Reactive Red 120, and rhodamine $\mathrm{B}$ ) and $\mathrm{H}_{2} \mathrm{O}_{2}$ solution $(30 \%, 12 \mu \mathrm{L})$. In the case of methylene blue, a methylene blue solution $(1 \mathrm{mM}, 50 \mu \mathrm{L})$ and an $\mathrm{H}_{2} \mathrm{O}_{2}$ solution $(1 \%, 5 \mu \mathrm{L})$ were mixed with $445 \mu \mathrm{L}$ of the redispersed $\mathrm{AgCl} @ \mathrm{AgAu}$ NPs solution. The photocatalytic degradation reactions were conducted under visible light irradiation 
for $3 \mathrm{~h}$ using a metal-halide lamp equipped with UV cut-off sheets $(\lambda>400 \mathrm{~nm})$. The degradation of organic dyes was analyzed by observing the changes in the characteristic absorption of each organic dye every 30 min using UV-vis spectroscopy.

\section{Conclusions}

The controlled synthesis of AgCl-based nanomaterials has been almost unexplored, or resulted in only limited success. The largest concern in this field has been the inherent chemical instability of $\mathrm{AgCl}$. Therefore, although particulate plasmonic structures are the most common in previous reports, their composition was mainly limited to Ag. Unlike previous studies, this work demonstrates a universal and straightforward route to synthesize bimetallic Ag and Au nanobumps on the surface of $\mathrm{AgCl}$ nanomaterials, which significantly expanded the window for visible light absorption. Importantly, the results shown in this work provide a facile approach to control the reduction of metal ions into nanostructured bumps with controlled and desired plasmonic properties at the interface of reducible solid $\mathrm{AgCl}$ and liquid water. We also demonstrate the correlation between the structural, compositional, and photocatalytic properties of AgCl-based nanomaterials. The extended visible light absorption range of the AgCl@AgAu NPs is highly advantageous for their enhanced photocatalytic properties because of the following two reasons. First, the significant red-shift of the absorption band $\left(\Delta \lambda_{\operatorname{MAX}}=\right.$ $\sim 200 \mathrm{~nm}$ ) implies the utilization of more energy, which would otherwise not have been used. Therefore, the AgCl@AgAu NPs, when used with conventional Ag/AgCl nanomaterials, would be an ideal combination for building up photocatalytic systems with efficient energy absorption. Second, the spectral irradiance of sunlight is higher in the ranges where the AgCl@AgAu NPs (550-650 nm) exhibit the absorption than in those of the conventional $\mathrm{Ag} / \mathrm{AgCl}$ nanomaterials $(\sim 400 \mathrm{~nm})$ [56]. Since sunlight is the ultimate source of visible light irradiation, the AgCl@AgAu NPs would be more appropriate for the decontamination of natural water than the conventional $\mathrm{Ag} / \mathrm{AgCl}$ nanomaterials. For practical applications in the future, large-scale synthesis and long-term stability of the AgCl@AgAu NPs need to be further investigated.

Supplementary Materials: The following are available online at http://www.mdpi.com/2073-4344/10/4/405/s1, Figure S1: The AgCl@AgAu NPs with different diameters were synthesized with different mole ratios of $\mathrm{AgNO}_{3}$ and $\mathrm{HAuCl}_{4}$. Figure S2: The AgCl@AgAu NPs synthesized with 55k PVP with different shapes., Figure S3: The stability of the AgCl@AgAu NPs with different shapes (shown in Figure S2) which were synthesized with different initial concentrations of 55k PVP.

Author Contributions: Conceptualization, H.-J.R., H.-L.K., and J.-S.L.; investigation, H.-J.R., H.-L.K., and J.H.J.; writing - original draft preparation, H.-J.R. and J.-S.L.; project administration, J.-S.L. All authors have read and agreed to the published version of the manuscript.

Funding: This research was funded by the NRF funded by the Korean government, MSIP (NRF-2015M3A9D7031015, NRF-2018R1A1A1A05079384, and NRF-2016R1A5A1010148).

Acknowledgments: The SEM images were obtained at the Seoul center of the Korea Basic Science Institute (KBSI, Republic of Korea).

Conflicts of Interest: The authors declare no conflict of interest.

\section{References}

1. Zumdahl, S.S.; Zumdahl, S.A. Chemistry, 8th ed.; Cengage Learning: Boston, MA, USA, 2010.

2. Garg, S.; Rong, H.Y.; Miller, C.J.; Waite, T.D. Chlorine-Mediated Regeneration of Semiconducting AgCl(s) Following Light-Induced Ag Formation: Implications to Contaminant Degradation. J. Phys. Chem. C 2016, 120, 5988-5996. [CrossRef]

3. Polk, B.J.; Stelzenmuller, A.; Mijares, G.; MacCrehan, W.; Gaitan, M. Ag/AgCl microelectrodes with improved stability for microfluidics. Sens. Actuator B Chem. 2006, 114, 239-247. [CrossRef]

4. Schurch, D.; Currao, A.; Sarkar, S.; Hodes, G.; Calzaferri, G. The Silver Chloride Photoanode in Photoelectrochemical Water Splitting. J. Phys. Chem. B 2002, 106, 12764-12775. [CrossRef] 
5. Joo, J.H.; Shin, H.; Kwon, K.; Hong, S.; Ryu, H.-J.; Choi, Y.; Lee, J.-S. Aqueous Synthesis of Highly Monodisperse Sub-100-nm AgCl Nanospheres/Cubes and Their Plasmonic Nanomesh Replicas as Visible-Light Photocatalysts and Single SERS Probes. Nanotechnology 2019, 30, 295604. [CrossRef] [PubMed]

6. Ryu, H.-J.; Shin, H.; Oh, S.; Joo, J.H.; Choi, Y.; Lee, J.-S. Wrapping AgCl Nanostructures with Trimetallic Nanomeshes for Plasmon-Enhanced Catalysis and in Situ SERS Monitoring of Chemical Reactions. ACS Appl. Mater. Interfaces 2020, 12, 2842-2853. [CrossRef] [PubMed]

7. Shen, Y.F.; Chen, P.L.; Xiao, D.; Chen, C.C.; Zhu, M.S.; Li, T.S.; Ma, W.G.; Liu, M.H. Spherical and Sheet like $\mathrm{Ag} / \mathrm{AgCl}$ Nanostructures: Interesting Photocatalysts with Unusual Facet-Dependent yet SubstrateSensitive Reactivity. Langmuir 2015, 31, 602-610. [CrossRef]

8. Kim, S.; Chung, H.; Kwon, J.H.; Yoon, H.G.; Kim, W. Facile Synthesis of Silver Chloride Nanocubes and Their Derivatives. Bull. Korean Chem. Soc. 2010, 31, 2918-2922. [CrossRef]

9. Peng, S.; Sun, Y.G. Ripening of bimodally distributed AgCl nanoparticles. J. Mater. Chem. 2011, 21, 11644-11650. [CrossRef]

10. Zhou, S.; Li, J.H.; Gilroy, K.D.; Tao, J.; Zhu, C.L.; Yang, X.; Sun, X.J.; Xia, Y.N. Facile Synthesis of Silver Nanocubes with Sharp Corners and Edges in an Aqueous Solution. ACS Nano 2016, 10, 9861-9870. [CrossRef]

11. Joo, J.H.; Kim, B.H.; Lee, J.S. Synthesis of Gold Nanoparticle-Embedded Silver Cubic Mesh Nanostructures Using AgCl Nanocubes for Plasmonic Photocatalysis. Small 2017, 13, 1701751. [CrossRef]

12. Chew, W.S.; Pedireddy, S.; Lee, Y.H.; Tjiu, W.W.; Liu, Y.J.; Yang, Z.; Ling, X.Y. Nanoporous Gold Nanoframes with Minimalistic Architectures: Lower Porosity Generates Stronger Surface-Enhanced Raman Scattering Capabilities. Chem. Mat. 2015, 27, 7827-7834. [CrossRef]

13. Pedireddy, S.; Lee, H.K.; Tjiu, W.W.; Phang, I.Y.; Tan, H.R.; Chua, S.Q.; Troadec, C.; Ling, X.Y. One-step synthesis of zero-dimensional hollow nanoporous gold nanoparticles with enhanced methanol electrooxidation performance. Nat. Commun. 2014, 5, 4947. [CrossRef] [PubMed]

14. Spagnoletti, F.N.; Spedalieri, C.; Kronberg, F.; Giacometti, R. Extracellular biosynthesis of bactericidal $\mathrm{Ag} / \mathrm{AgCl}$ nanoparticles for crop protection using the fungus Macrophomina phaseolina. J. Environ. Manag. 2019, 231, 457-466. [CrossRef] [PubMed]

15. Karimi, S.; Samimi, T. Green and simple synthesis route of $\mathrm{Ag} @ \mathrm{AgCl}$ nanomaterial using green marine crude extract and its application for sensitive and selective determination of mercury. Spectroc. Acta Part A Mol. Biomol. Spectr. 2019, 222, 117216. [CrossRef] [PubMed]

16. Kashyap, M.; Samadhiya, K.; Ghosh, A.; Anand, V.; Shirage, P.M.; Bala, K. Screening of microalgae for biosynthesis and optimization of $\mathrm{Ag} / \mathrm{AgCl}$ nano hybrids having antibacterial effect. RSC Adv. 2019, 9, 25583-25591. [CrossRef]

17. Gawali, P.; Jadhav, B.L. Synthesis of $\mathrm{Ag} / \mathrm{AgCl}$ Nanoparticles and their action on Human Serum albumin: A fluorescence study. Process Biochem. 2018, 69, 106-122. [CrossRef]

18. Zhang, H.J.; Chen, G.H.; Bahnemann, D.W. Photoelectrocatalytic materials for environmental applications. J. Mater. Chem. 2009, 19, 5089-5121. [CrossRef]

19. Reddy, P.A.K.; Reddy, P.V.L.; Kwon, E.; Kim, K.H.; Akter, T.; Kalagara, S. Recent advances in photocatalytic treatment of pollutants in aqueous media. Environ. Int. 2016, 91, 94-103. [CrossRef]

20. Garcia-Segura, S.; Brillas, E. Applied photoelectrocatalysis on the degradation of organic pollutants in wastewaters. J. Photochem. Photobiol. C Photochem. Rev. 2017, 31, 1-35. [CrossRef]

21. Gaya, U.I.; Abdullah, A.H. Heterogeneous photocatalytic degradation of organic contaminants over titanium dioxide: A review of fundamentals, progress and problems. J. Photochem. Photobiol. C Photochem. Rev. 2008, 9, 1-12. [CrossRef]

22. Tong, H.; Ouyang, S.X.; Bi, Y.P.; Umezawa, N.; Oshikiri, M.; Ye, J.H. Nano-photocatalytic Materials: Possibilities and Challenges. Adv. Mater. 2012, 24, 229-251. [CrossRef] [PubMed]

23. Chen, X.B.; Shen, S.H.; Guo, L.J.; Mao, S.S. Semiconductor-based Photocatalytic Hydrogen Generation. Chem. Rev. 2010, 110, 6503-6570. [CrossRef] [PubMed]

24. Ibhadon, A.O.; Fitzpatrick, P. Heterogeneous Photocatalysis: Recent Advances and Applications. Catalysts 2013, 3, 189-218. [CrossRef]

25. Fujishima, A.; Honda, K. Electrochemical Photolysis of Water at a Semiconductor Electrode. Nature 1972, 238, 37-38. [CrossRef] [PubMed] 
26. Ong, W.J.; Tan, L.L.; Chai, S.P.; Yong, S.T.; Mohamed, A.R. Facet-Dependent Photocatalytic Properties of $\mathrm{TiO}_{2}$-Based Composites for Energy Conversion and Environmental Remediation. Chemsuschem 2014, 7, 690-719. [CrossRef] [PubMed]

27. Holton, J.C. Encyclopedia of Atmospheric Sciences, 1st ed.; Academic Press: Cambridge, MA, USA, 2002.

28. Zhang, Y.; Wang, T.; Zhou, M.; Wang, Y.; Zhang, Z.M. Hydrothermal preparation of Ag-TiO 2 nanostructures with exposed $\{001\} /\{101\}$ facets for enhancing visible light photocatalytic activity. Ceram. Int. 2017, 43, 3118-3126. [CrossRef]

29. Anwer, S.; Bharath, G.; Iqbal, S.; Qian, H.M.; Masood, T.; Liao, K.; Cantwell, W.J.; Zhang, J.T.; Zheng, L.X. Synthesis of edge-site selectively deposited Au nanocrystals on $\mathrm{TiO}_{2}$ nanosheets: An efficient heterogeneous catalyst with enhanced visible-light photoactivity. Electrochim. Acta 2018, 283, 1095-1104. [CrossRef]

30. Messih, M.F.A.; Ahmed, M.A.; Soltan, A.; Anis, S.S. Facile approach for homogeneous dispersion of metallic silver nanoparticles on the surface of mesoporous titania for photocatalytic degradation of methylene blue and indigo carmine dyes. J. Photochem. Photobiol. A Chem. 2017, 335, 40-51. [CrossRef]

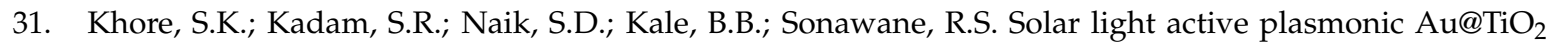
nanocomposite with superior photocatalytic performance for $\mathrm{H}_{2}$ production and pollutant degradation. New J. Chem. 2018, 42, 10958-10968. [CrossRef]

32. Koczkur, K.M.; Mourdikoudis, S.; Polavarapu, L.; Skrabalak, S.E. Polyvinylpyrrolidone (PVP) in nanoparticle synthesis. Dalton Trans. 2015, 44, 17883-17905. [CrossRef]

33. Zhang, Z.T.; Zhao, B.; Hu, L.M. PVP protective mechanism of ultrafine silver powder synthesized by chemical reduction processes. J. Solid State Chem. 1996, 121, 105-110. [CrossRef]

34. Lee, J.H.; Kim, G.H.; Nam, J.M. Directional Synthesis and Assembly of Bimetallic Nanosnowmen with DNA. J. Am. Chem. Soc. 2012, 134, 5456-5459. [CrossRef]

35. Banica, R.; Ursu, D.; Nyari, T.; Kellenberger, A. Polyol synthesis of silver nanowires in the presence of silver chloride. J. Optoelectron. Adv. Mater. 2017, 19, 266-271.

36. Wang, B.; Wang, D.D.; Zhao, S.; Huang, X.B.; Zhang, J.B.; Lv, Y.; Liu, X.C.; Lv, G.J.; Ma, X.J. Evaluate the ability of PVP to inhibit crystallization of amorphous solid dispersions by density functional theory and experimental verify. Eur. J. Pharm. Sci. 2017, 96, 45-52. [CrossRef] [PubMed]

37. Trasi, N.S.; Oucherif, K.A.; Litster, J.D.; Taylor, L.S. Evaluating the influence of polymers on nucleation and growth in supersaturated solutions of acetaminophen. CrystEngComm 2015, 17, 1242-1248. [CrossRef]

38. Jukic, M.; Sviben, I.; Zoric, Z.; Milardovic, S. Effect of Polyvinylpyrrolidone on the Formation AgBr Grains in Gelatine Media. Croat. Chem. Acta 2012, 85, 269-276. [CrossRef]

39. Gupta, V.K.; Jain, R.; Mittal, A.; Saleh, T.A.; Nayak, A.; Agarwal, S.; Sikarwar, S. Photo-catalytic degradation of toxic dye amaranth on $\mathrm{TiO}_{2} / \mathrm{UV}$ in aqueous suspensions. Mater. Sci. Eng. C Mater. Biol. Appl. 2012, 32, 12-17. [CrossRef]

40. Rimer, J.D.; Chawla, A.; Le, T.T. Crystal Engineering for Catalysis. Annu. Rev. Chem. Biomol. Eng. 2018, 9, 283-309. [CrossRef]

41. Karkmaz, M.; Puzenat, E.; Guillard, C.; Herrmann, J.M. Photocatalytic degradation of the alimentary azo dye amaranth mineralization of the azo group to nitrogen. Appl. Catal. B Environ. 2004, 51, 183-194. [CrossRef]

42. Byeon, J.H.; Park, J.H.; Hwang, J.H. Spark generation of monometallic and bimetallic aerosol nanoparticles. J. Aerosol. Sci. 2008, 39, 888-896. [CrossRef]

43. Ji, X.H.; Song, X.N.; Li, J.; Bai, Y.B.; Yang, W.S.; Peng, X.G. Size control of gold nanocrystals in citrate reduction: The third role of citrate. J. Am. Chem. Soc. 2007, 129, 13939-13948. [CrossRef] [PubMed]

44. Wang, S.; Qian, K.; Bi, X.Z.; Huang, W.X. Influence of Speciation of Aqueous $\mathrm{HAuCl}_{4}$ on the Synthesis, Structure, and Property of Au Colloids. J. Phys. Chem. C 2009, 113, 6505-6510. [CrossRef]

45. McKeehan, L.W. The crystal structure of silver-palladium and silver-gold alloys. Phys. Rev. 1922, 20, 424-432. [CrossRef]

46. Storhoff, J.J.; Lazarides, A.A.; Mucic, R.C.; Mirkin, C.A.; Letsinger, R.L.; Schatz, G.C. What controls the optical properties of DNA-linked gold nanoparticle assemblies? J. Am. Chem. Soc. 2000, 122, 4640-4650. [CrossRef]

47. Lin, Z.Y.; Xiao, J.; Yan, J.H.; Liu, P.; Li, L.H.; Yang, G.W. Ag/AgCl plasmonic cubes with ultrahigh activity as advanced visible-light photocatalysts for photodegrading dyes. J. Mater. Chem. A 2015, 3, 7649-7658. [CrossRef] 
48. Wang, L.; Shi, Y.L.; Wang, T.F.; Zhang, L.L. Silver chloride enwrapped silver grafted on nitrogen-doped reduced graphene oxide as a highly efficient visible-light-driven photocatalyst. J. Colloid Interface Sci. 2017, 505, 421-429. [CrossRef]

49. Daupor, H.; Wongnawa, S. Urchinlike $\mathrm{Ag} / \mathrm{AgCl}$ photocatalyst: Synthesis, characterization, and activity. Appl. Catal. A Gen. 2014, 473, 59-69. [CrossRef]

50. Saleh, T.A.; Gupta, V.K. Functionalization of tungsten oxide into MWCNT and its application for sunlight-induced degradation of rhodamine B. J. Colloid Interface Sci. 2011, 362, 337-344. [CrossRef]

51. Subash, B.; Krishnakumar, B.; Swaminathan, M.; Shanthi, M. Highly Efficient, Solar Active, and Reusable Photocatalyst: Zr-Loaded Ag-ZnO for Reactive Red 120 Dye Degradation with Synergistic Effect and Dye-Sensitized Mechanism. Langmuir 2013, 29, 939-949. [CrossRef]

52. Khan, M.M.; Lee, J.; Cho, M.H. Au@TiO 2 nanocomposites for the catalytic degradation of methyl orange and methylene blue: An electron relay effect. J. Ind. Eng. Chem. 2014, 20, 1584-1590. [CrossRef]

53. Wang, C.C.; Li, J.R.; Lv, X.L.; Zhang, Y.Q.; Guo, G.S. Photocatalytic organic pollutants degradation in metal-organic frameworks. Energy Environ. Sci. 2014, 7, 2831-2867. [CrossRef]

54. Li, Z.X.; Luo, D.; Li, M.M.; Xing, X.F.; Ma, Z.Z.; Xu, H. Recyclable $\mathrm{Fe}_{3} \mathrm{O}_{4}$ Nanoparticles Catalysts for Aza-Michael Addition of Acryl Amides by Magnetic Field. Catalysts 2017, 7, 219. [CrossRef]

55. Astruc, D.; Lu, F.; Aranzaes, J.R. Nanoparticles as recyclable catalysts: The frontier between homogeneous and heterogeneous catalysis. Angew. Chem. Int. Ed. 2005, 44, 7852-7872. [CrossRef] [PubMed]

56. Davy, N.C.; Sezen-Edmonds, M.; Gao, J.; Lin, X.; Liu, A.; Yao, N.; Kahn, A.; Loo, Y.L. Pairing of near-ultraviolet solar cells with electrochromic windows for smart management of the solar spectrum. Nat. Energy 2017, 2, 17104. [CrossRef]

(C) 2020 by the authors. Licensee MDPI, Basel, Switzerland. This article is an open access article distributed under the terms and conditions of the Creative Commons Attribution (CC BY) license (http://creativecommons.org/licenses/by/4.0/). 